\title{
Prior Telephone Confirmation to Reduce Absenteeism in Oncological Surgeries: A Phone Call That Saves
}

\section{Lives}

\author{
Danielly Acioli Galvão de Souza ${ }^{1}$, Joseli Soares Brazorotto ${ }^{1}$, Erika Maria Araújo Barbosa de Sena ${ }^{2}$, Talita Lúcio \\ Chaves Vasconcelos ${ }^{3}$, Breno Carvalho de Medeiros ${ }^{4}$, Amália Cinhtia Meneses Rêgo ${ }^{5}$, Irami Araújo-Filho ${ }^{* 6}$ \\ ${ }^{1}$ Postgraduate Program in Health Management and Innovation - Federal University of Rio Grande do Norte - \\ UFRN/EBSERH - Brazilian Company of Hospital Services; \\ ${ }^{2}$ Nurse at Professor Alberto Antunes University Hospital-HUPAA / UFAL; Master in Nursing from the Federal University \\ of Alagoas-UFAL - Brazil; \\ ${ }^{3}$ Professor at the Federal Institute of Alagoas-IFAL; Master in Nursing from the Federal University of Alagoas-UFAL - \\ Brazil; \\ ${ }^{4}$ Graduating in Civil Engineering at the Federal University of Pernambuco - UFPE - Brazil. \\ ${ }^{5}$ Postgraduate Program in Biotechnology at Potiguar University / UnP - Laureate International Universities. Teaching and \\ Research Manager - School of Health - League Against Cancer Natal - RN / Brazil. Ph.D. in Health Science. \\ ${ }^{6}$ Postgraduate Program in Biotechnology at Potiguar University/ UnP - Laureate International Universities. Postgraduate \\ Program in Health Management and Innovation - Federal University of Rio Grande do Norte - UFRN/EBSERH - Brazilian \\ Company of Hospital Services; Full Professor Department of Surgery, Federal University of Rio Grande do Norte. Full \\ Professor, Department of Surgery, Potiguar University. Ph.D in Health Science/ Natal-RN, Brazil
}

Corresponding author: Irami Araújo-Filho, MD, Ph.D.; https://orcid.org/0000-0003-2471-7447; CV: http://lattes.cnpq.br/3975706297235540; https://www.researchgate.net/profile/Irami_Filho; https://publons.com/researcher/1338886/irami-araujo-filho/; Email: irami.filho@uol.com.br

Received 16 December 2019;

Accepted 23 December 2019;

Published 31 December 2019

\begin{abstract}
In assessing the quality of health services, the use of quality and resolution indicators used in the operating room stands out. The cancellation fee for operating procedures is one of the most important. Cancellations interfere with the outcome of care and increase hospital costs. In the case of cancer patients, the consequences are severe, since early surgical intervention directly influences prognosis, reducing morbidity, and mortality. Considering that surgical suspensions should be prevented, pre-anesthetic consultation and telephone confirmation days before the procedure configure strategies that can be adopted to minimize the problem. A descriptive observational study with a quantitative approach was conducted on the impact of previous telephone confirmation on the reduction of cancellation of oncologic surgeries due to absenteeism. The research was carried out at Professor Alberto Antunes University Hospital, Federal University of Alagoas (HUPAA/UFAL), city of Maceió, State of Alagoas, Northeastern Brazil. The sample consisted of 205 patients with scheduled cancer surgery from January to June 2019, after approval by the Institutional Ethics Committee. Data analysis was performed descriptively. The effectiveness of previous telephone confirmation was verified, with a 50\% reduction in cancellation of elective oncologic surgeries due to absenteeism. The implementation of a call center to confirm the presence of the user consisted of an impact strategy in reducing the cancellation of previously scheduled cancer surgeries.
\end{abstract}

Keywords: operating rooms, surgery, surgical oncology, operative surgical procedure, operative procedures; absenteeism.

\section{Introduction}

Quality management in health services is becoming increasingly important to offer better care, combined with scientific and technological advances. In the evaluation of health care, the use of indicators stands out, among them, the cancellation rate of operative procedures that measures the quality and resolution of the operating room ${ }^{[1,2]}$. Surgical cancellation is defined as an operation that has been scheduled but not performed. This involves medical, 
hospital, or patient-related reasons ${ }^{[3]}$. Cancellations cause harm to the patient, interfere with the outcome of care, and increase hospital costs ${ }^{[4,5]}$. Regarding the cancer patient, the consequences are severe, since early surgical intervention directly influences prognosis, increases survival, and reduces morbidity and mortality. Law No. 12.732, of November 2012, of the Brazilian Ministry of Health, ratifies the importance of this intervention, guaranteeing the cancer patient the right to start treatment within 60 (sixty) days after confirmation of the diagnosis ${ }^{[6]}$. Thus, the analysis of the surgical suspension rate in a health unit aims to improve the quality of care and efficiency of the service offered to the population of the Unified Health System (SUS/Brazil) associated with the rationalization of human and financial resources ${ }^{[2]}$. The costs of surgical procedures represent about $40 \%$ of total hospital expenses. Inadequate management promotes a negative impact on the care of patients with surgical pathologies, in particular, cancer patients who require surgery ${ }^{[7]}$. According to the Australian Department of Health, the surgical suspension rate should be less than $2 \%$ for any reason, less than $1 \%$ due to medical reasons, and less than $0.5 \%$ due to patient absenteeism ${ }^{[8]}$. According to the idea that surgical suspensions should be prevented, Santos et al. demonstrated that pre-anesthetic consultation and prior telephone confirmation two days before surgery were strategies that could be adopted to minimize cancellation due to absenteeism ${ }^{[9]}$. Obtaining a detailed clinical history of the patient during pre-anesthetic consultation is associated with excellent results and prevention of surgical suspensions, with the improvement of the quality of preoperative preparation $^{[10,11]}$. Haufler et al. noted that three of the top ten reasons for surgery suspension were related to the patient's preoperative orientation regarding the scheduled procedure: absenteeism, noncompliance with fasting restrictions, and lack of a responsible adult to monitor the patient ${ }^{[12]}$. After the implementation of telephone calls three days before surgery, with clarification on preoperative patients, the study was able to reduce by $54 \%$ the number of surgical cancellations compared to the previous year ${ }^{[12]}$. There are numerous purposes for patient interactions via telephone contact. Counseling, evaluation, and screening for different care routes are performed ${ }^{[10]}$. Better communication with the patient facilitates compliance with scheduled procedures and reduces surgical suspensions ${ }^{[13]}$. Abdulaziz and Paschoal reported the following reasons for surgical cancellation related to patient absenteeism: lack of date of surgery, personal and health problems, socio-economic rights, and hospital cancellation ${ }^{[13-15]}$. The suspension rate of cancer surgeries in the last three years was between 33\% and 36\% at Professor Alberto Antunes University Hospital (SOUL System/MV Hospitalar®). In this context, the present study evaluated the impact of prior telephone confirmation on reducing the cancellation of elective oncologic surgeries due to patient absenteeism to compare whether this indicator improved compared to periods before the study.

\section{Methods}

A descriptive observational study with a quantitative approach was conducted on the impact of previous telephone confirmation on reducing the cancellation of absenteeism surgery. The research was carried out at Professor Alberto Antunes University Hospital, Federal University of Alagoas (HUPAA / UFAL), located in the city of Maceió, Alagoas State, Northeastern Brazil. HUPAA is the largest public health institution in the state due to its physical area, clinical staff, and the development of undergraduate, postgraduate, research, and care activities. HUPAA is a state reference in the treatment of cancer patients. The HUPAA surgical center is composed of seven operative rooms for cancer surgery. The initial study sample consisted of 444 patients, with oncologic surgery scheduled for the period between January and June 2019. Of this total, 205 patients participated in the study after applying the exclusion criteria. The study excluded 26 patients who did not have telephone contact; 101 who did not answer the call after the third contact; 9 patients under 18 years old; 65 patients who were already in the hospital during communication and 38 patients scheduled within 48 hours of surgery. After approval by the Ethics and Research Committee of the Federal University of Alagoas / UFAL (CAAE $n^{\circ}$ 02833318.8.0000.5013), telephone calls were made to the research participants who signed the Informed Consent Form (ICF) at the last preoperative consultation with the surgeon, authorizing participation in the study. Patient data and several surgeries were collected through the SOUL MV Hospitalar® System. The number of cancer surgeries from the same period of the last three years was collected. Through this, it was possible to access the nominal list of patients with operations performed or suspended. In the case of patients who did not present the description of the surgery as being cancer or not, it was necessary to access their electronic medical record, ratifying the information through the report of the operation or evolution, in cases of suspension. By telephone contact made $48 \mathrm{~h}$ before surgery, the user was asked about complementary exams, fasting, use of medications, orthoses/prostheses, and confirmation of their presence in the surgical procedure through a validated questionnaire $^{[11]}$. The calls were made from Monday to Friday from $7-18 \mathrm{~h}$. For surgeries scheduled on Mondays, the requests were made on Fridays before the procedures. Nine cases of absenteeism were reported to the surgeon in charge, with $22.22 \%$ of patients being replaced. The variables evaluated in the present study were: oncologic surgical suspension rate, oncologic patient absenteeism, users who received calls for oncologic surgical specialty, users who confirmed absenteeism, and users who were replaced after confirmation of absenteeism. The rate of surgical suspension was calculated by the number of surgeries suspended divided by the total number of scheduled operations, within the defined period for the study, and multiplied by 100 . The results were then presented in percentages, according to Ministry norms of Brazilian Health [16].

\section{Results}

During the study period, 435 elective oncologic surgeries were scheduled by ten surgical subspecialties. The number of canceled operations was 90(20.69\%), with an average of 3.6 cases/day. Regarding the causes of cancellation, 19(20\%) were related to the clinical condition of the patient; 13(14\%) lack of hospital beds and materials. Patient non-attendance after telephone intervention represented the fourth cause of surgical cancellation, in a total of 7 cases $(8 \%)$. Compared to the last three years, the rate of medical suspension due to absenteeism ranged from $16 \%-26 \%$, reaching a higher value in 2017. Between 2018-2019, there was a 50\% reduction after the implementation of prior communication by telephone (Figure 1). 


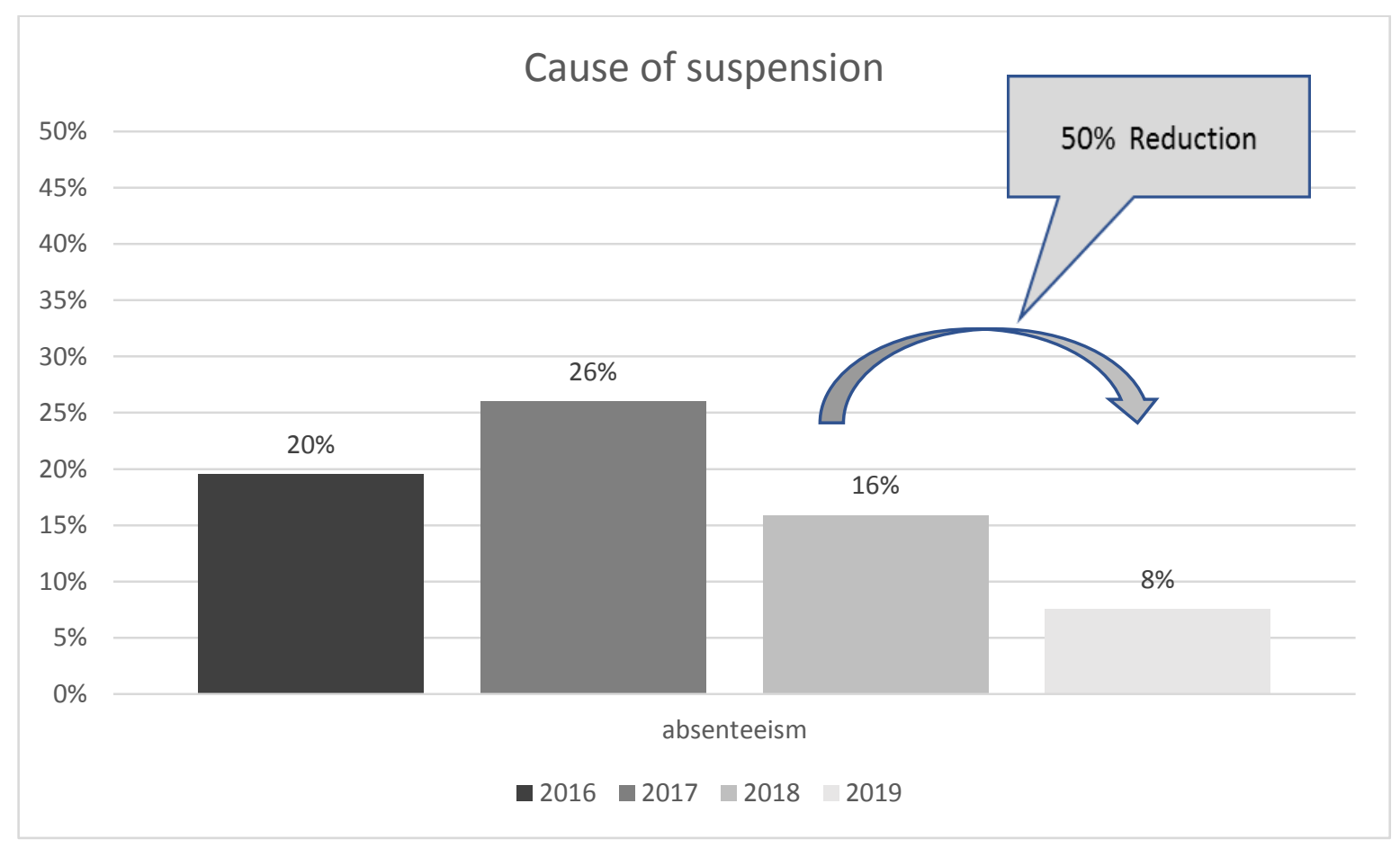

Figure 1: Surgical suspension rate 2016-2019.

The analysis of the year because of the suspension of 2019 (Figure 2), represented by the Pareto diagram, it is seen that almost half of the suspensions were associated with clinical patients and institutional factors such as lack of material and hospital bed.

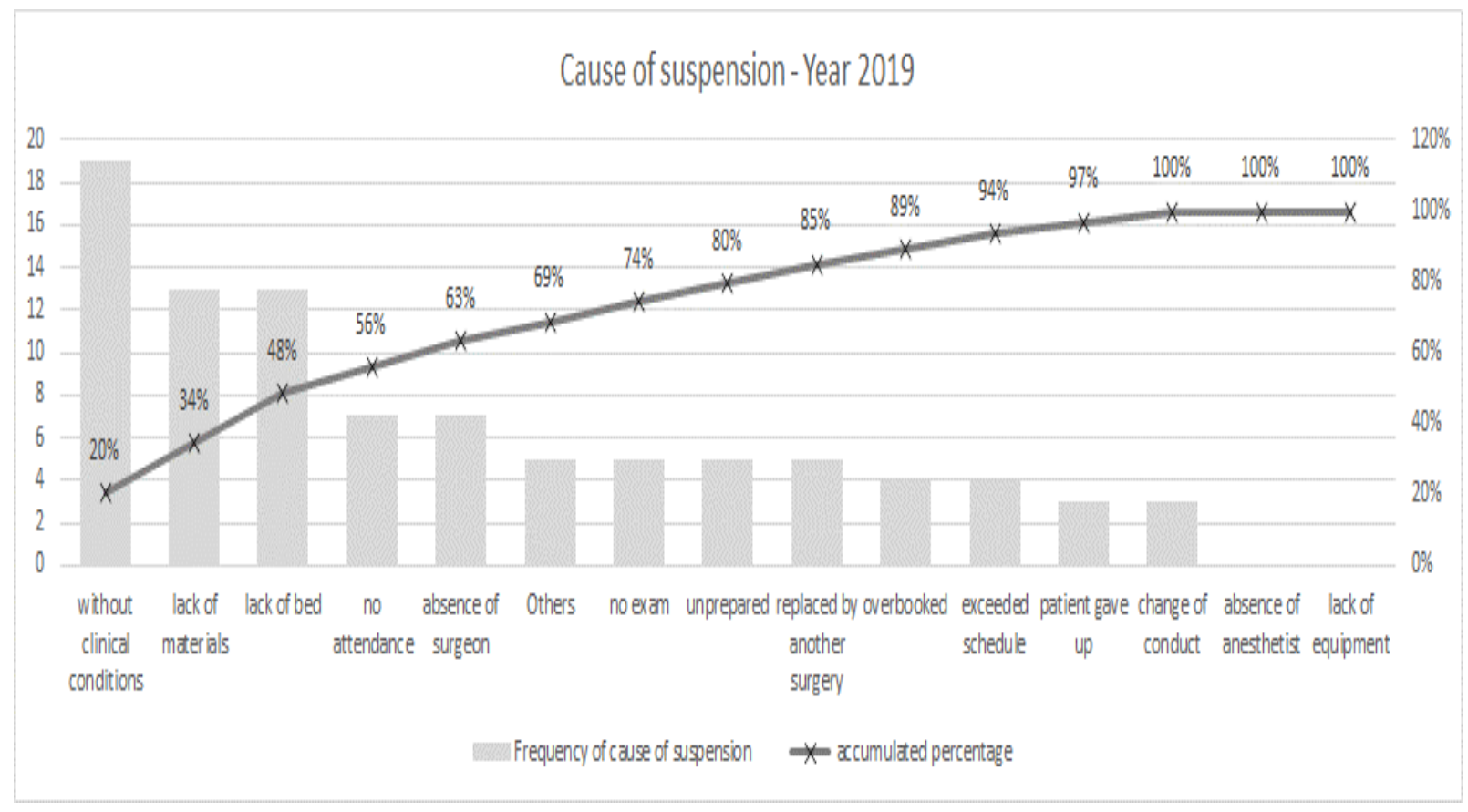

Figure 2: Causes of surgery suspension - 2019.

According to the distribution of cases canceled by specialty, the highest frequency of cancellations was attributed to gynecology, dermatology, and head and neck, all with $20 \%$ (08), followed by urology, 15\% (04); and gastrointestinal surgery with 10\% (04). Regarding the users who received calls to confirm elective surgery, the following are the quantitative according to oncological surgical specialty: gynecology (28.93\%); dermatology (27.92\%); head and neck (14.21\%); urology (11.67\%); coloproctology (4.57\%); thoracic surgery (2.54\%); gastrointestinal (3.55\%); ophthalmology
(2.03\%); neurology $(1.52 \%)$; others $(3.04 \%)$. Of these users, 197 confirmed attendance on the day of surgery, $100 \%$ said they had no health problems other than surgical pathology, 92.89\% had all preoperative examinations, $44.16 \%$ had pre-anesthetic consultation. Regarding fasting orientations, $79.19 \%$ reported being oriented about it, while $20.81 \%$ did not report previous orientation. Finally, $62.44 \%$ reported medication use, as well as $43.15 \%$, had orthosis/prosthesis. 


\section{Surgical Confirmation x Surgical Suspension - Year 2019}

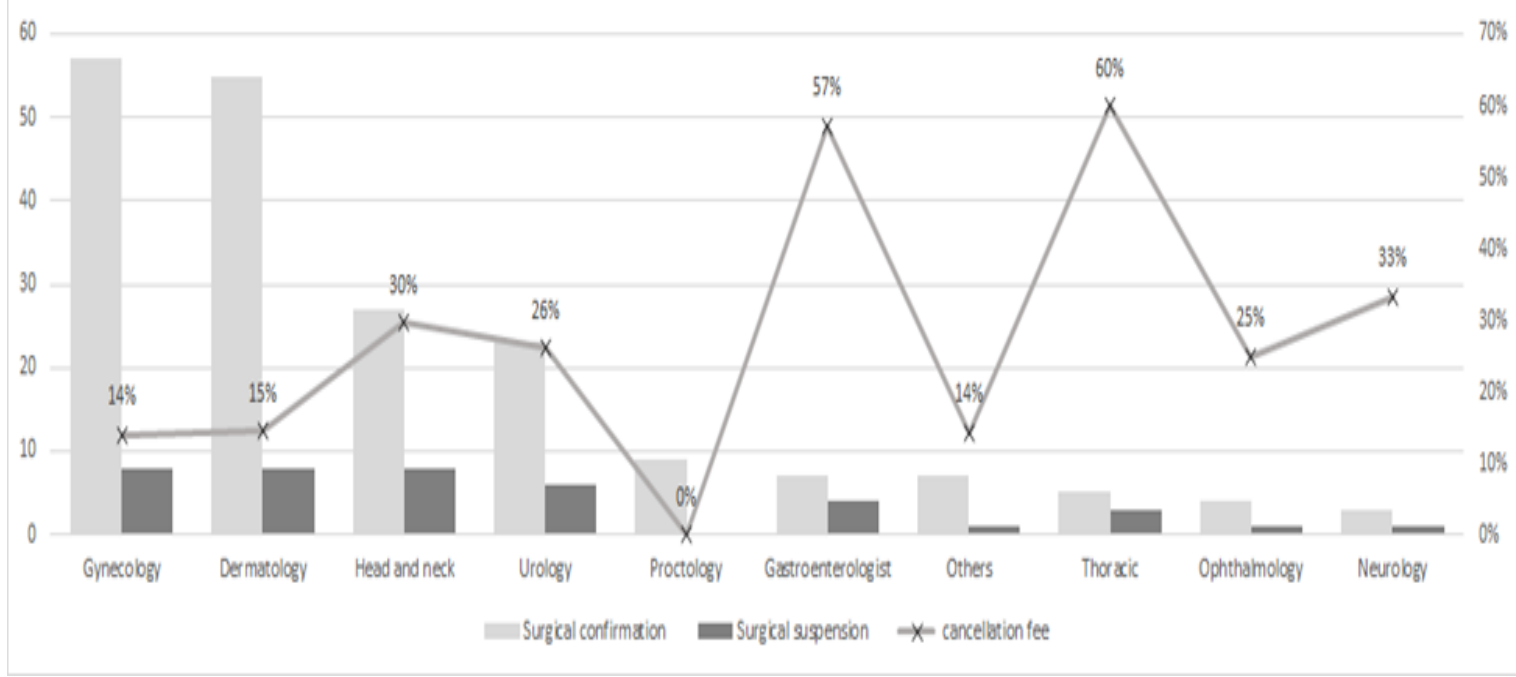

Figure 3: Percentage of patients with prior surgical confirmation/specialty.

\section{Discussion}

During the study period, the surgical suspension rate reached $20.69 \%$. The frequency of cancellation of surgeries in different countries ranges from $1 \%-30 \% 8$, as well as similar cancellation rates ranging from $17.6 \%-26 \%{ }^{[3,11,17,18]}$. However, in some Brazilian university hospitals, the percentage is slightly below, between $16.1 \%-17.3 \%^{[19]}$. It should be emphasized that from a quality management standpoint, a low rate of surgical cancellation is an indicator of the efficient use of a surgical unit and the hospital's financial resources ${ }^{[3]}$. Regarding the leading causes of cancellation after previous telephone intervention, 19 cases $(20 \%)$ were related to the patient's clinical condition; 13 (14\%), lack of bed and materials; and 7 (8\%), for not attending the patient. In this sense, absenteeism was the leading cause of surgical suspension in recent years, with values of 26\% in 2017; and 16\% in 2018. According to Appavu et al., There was also a prevalence of patient non-attendance in their study (about 65\%), as reported by Abeeleh (62.52\%), Mesmar (23\%), Kumar (19\%), Ávila (18.1\%), Morris $(16.8 \%)$ and Garg (16.2\%) respectively ${ }^{[3,11-13,17,20-22]}$. As an intervention measure to reduce late cancellation rates, preoperative telephone contact is useful. Avila et al., through preoperative telephone calls, reduced the cancellation rate from $18 \%$ to $5.4 \%{ }^{[11]}$ while Kaye et al. reported a reduction from $26 \%$ to $10.8 \%$ in surgical suspension due to patient absenteeism ${ }^{[23]}$. In this study, after the previous telephone call, there was a significant reduction in cancellations due to non-attendance from $16 \%$ in 2018 to $8 \%$ after telephone contact / 2019. Analysis by surgical specialties, no article was found that reported suspension of oncologic surgeries. Thus, the analogy with other studies could not be performed. The highest frequency of cancellations was attributed to gynecological, dermatology, and head and neck surgeries, all with 20\% (08); followed by urology, with $15 \%$ (04); and gastrointestinal system, $10 \%$ (04). A study conducted in a tertiary hospital located in the Middle East, gynecology had the lowest percentage (2\%); urology, the largest $(7.7 \%)^{[24]}$. These results are similar to the Kumar study, where gynecology obtained the lowest percentage, with $1.15 \%$, and urology was among the three most abundant, with $2.1 \%{ }^{[17]}$. Regarding the previous telephone call, when asked about fasting guidelines, $79.19 \%$ of patients reported being oriented, while $20.81 \%$ reported no guidance. Gaucher et al., in turn, published in their study that $20 \%$ of users said they did not fully understand the instructions on the need for fasting ${ }^{[24]}$. Another question made through previous telephone contact was the pre-anesthetic consultation: $44.16 \%$ of the patients were evaluated, $36.04 \%$ did not have the discussion, and in $19.80 \%$, it was not possible to verify whether or not there was. However, it is a mandatory assessment before any elective surgery, ensuring knowledge of the patient's clinical status, as well as providing safety and comfort during the surgical procedure ${ }^{[25]}$.

\section{Conclusion}

Given the above data, it was found the effectiveness of previous telephone confirmation in reducing the cancellation of elective cancer surgery due to the absenteeism of the patient, given the $50 \%$ reduction in cancellations related to this cause. As presented, the $16 \%$ registered in 2018 were replaced by $8 \%$, after the telephone contact was made, in the same evaluation period / 2019. In this sense, we highlight as relevant the number of patients not located, represented by those who did not have telephone contact $(5.8 \%)$ or who did not answer the call $(22.7 \%)$. Alternatively, it is feasible to increase the timeframe for the previous request to three days before surgery. The likelihood of contact with the patient and consequent replacement in cases of confirmed absenteeism becomes greater. Besides, it is necessary to update patient registration data in electronic databases, making communication more effective. Despite the guidance provided through telephone contact regarding fasting, medication use, and confirmation about preoperative examinations, there was an increase in suspensions due to lack of preparation or due to the patient not having adequate clinical conditions for the procedure, corroborating the importance preanesthetic consultation. In this context, it is recognized that the analysis of cancellation causes is essential for the efficient and productive use of operating rooms. Thus, the implementation of a call center to confirm the presence of the user, and increased coverage of pre-anesthetic evaluation, would be a strategy of significant impact in reducing surgical cancellation. The adoption of these measures would reflect on the leading causes of abandonment identified by the study. In conclusion, considering that cancer diseases require early surgical intervention, the above measures tend to directly influence patients' prognosis, improving survival and reducing morbidity and mortality.

\section{Compliance with ethical standards}




\section{Acknowledgments}

The authors thank the Ph.D. in Health Sciences and Teaching and Research Manager at League Against Cancer, Profa. Dra. Amália Rêgo, for her contribution and relevance to the scientific discussion and supervision of this research, acting as an expert consultant on the bibliographic survey, analysis, and scientific advice. We also thank all the study components for their dedication and effort to build a scientifically validated quality study.

\section{Disclosure of conflict of interest}

There are no conflicts of interest to declare by any of the authors of this study.

\section{References}

[1] Pinheiro SL, Vasconcelos RO, Oliveira JLC, Matos FGOA, Tonini NS, Alves DCI. Surgical cancellation rate: quality indicator at a public university hospital. REME - Rev Min Enferm. 2017. DOI: 10.5935/14152762.20170024.

[2] Landim FM, Paiva FD, Fiuza ML, Oliveira EP, Pereira JG, Siqueira Ide A. Analyses of the related factors for surgery suspension at a general surgery service of medium complexity]. Rev Col Bras Cir. 2009;36(4):2837.

[3] Appavu ST, Al-Shekaili SM, Al-Sharif AM, Elawdy MM. The Burden of Surgical Cancellations and NoShows: Quality management study from a large regional hospital in Oman. Sultan Qaboos Univ Med J. 2016;16(3):e298-302.

doi: 10.18295/squmj.2016.16.03.006.

[4] Sampaio CEP; Gonçalves RA; e Júnior HCS. Determination of surgery suspension factors and their constributions with nursing assistance. Care Online. 2016; 8(3):4813-4820. DOI: $10.9789 / 2175-$ 5361.2016.v8i3.4813-4820.

[5] Moraes PGS, Pachêco NMD, Souza e Silva RG. Clinical and organizational factors related to the suspension of surgical procedures. Journal of Nursing UFPE. 2017, 11(7),645-53. DOI: 10.5205/reuol.10939-97553-1RV.1107201701.

[6] Souza CB, Fustinoni SM, Amorim MHC, Zandonade E, Matos JC, Schirmer J. Breast cancer: diagnosis-totreatment waiting times for elderly women at a reference hospital of São Paulo, Brazil. Ciênc. saúde coletiva. 2015;20(12),3805-3816.

doi:10.1590/1413812320152012.00422015 .

[7] Carvalho TA, Sobral CB, Marinho PML, LlapaRodriguez EO, Aguiar Campos MP. Suspensão de cirurgias em um hospital universitário. Rev. Sobecc. 2016,21(4),186-191.

[8] Dhafar KO, Ulmalki MA, Felemban MA, Mahfouz ME, Baljoon MJ, Gazzaz ZJ, Baig M, Hamish NM, AlThobaiti SA, Al-Hothali FT. Cancellation of operations in Saudi Arabian hospitals: Frequency, reasons and suggestions for improvements. Pak J Med Sci. 2015;31(5):1027-32. doi: 10.12669/pjms.315.7932.

[9] Santos GAAC, Bocchi SCM. Cancellation of elective surgeries in a Brazilian public hospital: reasons and estimated reduction. Rev Bras Enferm. 2017;70(3):535-
42. DOI: http://dx.doi.org/10.1590/0034-7167-20160084 .

[10] Ludbrook G, Seglenieks R, Osborn S, Grant C. A call centre and extended checklist for pre-screening elective surgical patients - a pilot study. BMC Anesthesiol. 2015;19; 15:77. doi: 10.1186/s12871-015-0057-1.

[11] de Avila MA, Bocchi SC. [Telephone confirmation of a patient's intent to be present for elective surgery as a strategy to reduce absenteeism]. Rev Esc Enferm USP. 2013;47(1):193-7.

[12] Haufler K, Harrington M. Using nurse-to-patient telephone calls to reduce day-of-surgery cancellations. AORN J. 2011;94(1):19-26. doi: 10.1016/j.aorn.2010.12.024

[13] Garg R, Bhalotra AR, Bhadoria P, Gupta N, Anand R. Reasons for cancellation of cases on the day of surgery-a prospective study. Indian J Anaesth. 2009;53(1):35-9.

[14] Elawdy MM. No-show as a cause of surgical cancellation: A mini review from a Middle Eastern perspective. Saudi J Anaesth. 2017;11(2):262-263. doi: 10.4103/sja.SJA_8_17.

[15] Barbosa FT, Souza DA. Frequência do uso adequado dos testes estatísticos nos artigos originais publicados na Revista Brasileira de Anestesiologia entre janeiro de 2008 e dezembro de 2009. Rev. Bras. Anestesiol. 2010; 60(5):528-536. doi:10.1590/S0034-70942010000500009.

[16] Barbosa MH, Miranda Goulart DM, Vieira de Andrade E, De Mattia, AL. Análise da suspensão de cirurgias em um hospital de ensino. Enfermería Global. 2012, 26(4), 174-183.

[17] Kumar R, Gandhi R. Reasons for cancellation of operation on the day of intended surgery in a multidisciplinary 500 bedded hospital. J Anaesthesiol Clin Pharmacol. 2012;28(1):66-9. doi: 10.4103/09709185.92442.

[18] Chalya PL, Gilyoma JM, Mabula JB, Simbila S, Ngayomela IH, Chandika AB, Mahalu W. Incidence, causes and pattern of cancellation of elective surgical operations in a university teaching hospital in the Lake Zone, Tanzania. Afr Health Sci. 2011;11(3):438-43.

[19] Santos GAACD, Bocchi SCM. Cancellation of elective surgeries in a Brazilian public hospital: reasons and estimated reduction. Rev Bras Enferm. 2017;70(3):535542. doi: 10.1590/0034-7167-2016-0084.

[20] Abeeleh MA, Tareef TM, Hani AB, Albsoul N, Samarah OQ, ElMohtaseb MS, Alshehabat M, Ismail ZB, Alnoubani O, Obeidat SS, Halawa SA. Reasons for operation cancellations at a teaching hospital: prioritizing areas of improvement. Ann Surg Treat Res. 2017;93(2):65-69. doi: 10.4174/astr.2017.93.2.65.

[21] Morris AJ, McAvoy J, Dweik D, Ferrigno M, Macario A, Haisjackl M. Cancellation of Elective Cases in a Recently Opened, Tertiary/Quaternary-Level Hospital in the Middle East. Anesth Analg. 2017;125(1):268-271. doi: 10.1213/ANE.0000000000002104.

[22] Mesmar M, Shatnawi NJ, Faori I, Khader YS. Reasons for cancellation of elective operations at a major teaching referral hospital in Jordan. East Mediterr Health J. 2011;17(8):651-5.

[23] Roxbury CR, Shah J, Tang D, Kshettry VR, Recinos PF, Woodard TD, Taylor M, Sindwani R. Analysis of 24hour surgical cancellations in an academic rhinology and 
skull base surgery practice. Int Forum Allergy Rhinol. 2019;9(3):298-304. doi: 10.1002/alr.22247.

[24] Al Talalwah N, McIltrot KH, Al Ghamdi A. Elective Surgical Cancellations in a Tertiary Hospital in the Middle East: Quality Improvement Process. J Perianesth
Nurs.

2019;34(2):310-321

doi:

10.1016/j.jopan.2018.05.016.

[25] Mendes FF, Machado EL, Oliveira M, Fernando BR, Eizerik G, Telöken PE. Preoperative evaluation: screening using a questionnaire. Rev. Bras.Anestesiol. 2013; 63(4):347-352.doi: 10.1016/j.bjan.2012.07.005. 